\title{
Reflections of a Practitioner-Researcher in the Field of Widening Participation in Arts Education
}

\author{
Martell Baines ${ }^{1, *}$ and Margaret Gregson ${ }^{2}$ (D) \\ 1 Progression Team, Leeds Arts University, Blenheim Walk, Leeds LS2 9AQ, UK \\ 2 School of Education, Faculty of Education and Society, University of Sunderland, St. Peter's Campus, \\ St. Peter's Way, Sunderland SR6 0DD, UK; maggie.gregson@sunderland.ac.uk \\ * Correspondence: Martell.baines@Leeds-art.ac.uk
}

Received: 22 February 2020; Accepted: 3 May 2020; Published: 9 May 2020

\begin{abstract}
This article provides an auto-ethnographic narrative to offer insights into my experience as a practitioner-researcher working in widening participation (WP) in post-compulsory education (PCE). It relates how I came to join the Education and Training Foundation (ETF) Practitioner Research Programme (PRP). It provides insights into the role of WP practitioner and manager and offers a reflection upon my experiences as an early practitioner-researcher conducting research in the field of WP. Writing in the first person, I reflect upon the positionality within my professional practice as someone who is immersed in the context that is being researched. I make my story as authentic as possible in order to throw new light upon knowledge in the field of widening participation (WP) practice. This immersion has enabled me to increase my professional knowledge and to establish a stronger voice in and for WP practitioners in the profession and for learners in the WP community. This empowerment has come about as my knowledge of the factors influencing the context of my work has expanded. I hope that it will be of interest to other researchers working in the field of WP and that they will accept my invitation to contribute to this conversation and reflect upon their own journey.
\end{abstract}

Keywords: practitioner researcher; reflective practice; auto-ethnography; widening participation; access; arts; social mobility; narrative; stories

\section{Introduction}

In this article, I present an auto-ethnographic narrative to present a self-reflective case study of a practitioner-researcher and a full-time widening participation (WP) manager working in the field of WP in post-compulsory education (PCE). This is intended to provide you, the reader, with some insights into an individual's experience of developing practitioner-researcher skills whilst engaged in a higher education (HE)-supported programme of research.

\section{Context}

To provide a context: The location of my current role is in an arts specialist education institution in the North of England. The university offers a range of creative arts courses, with entry points at several stages of compulsory and post-compulsory education, through the provision of both further and higher education courses. I had migrated into WP from being an academic and a programme leader in a Contemporary Fine Arts Practice undergraduate degree. This had involved providing a great deal of support to encourage the development of agency among marginalised students in order to enable them to succeed in their studies. I had found that once students were falling behind on a submission for an assessment or due to being unable to attend for whatever reason, it increasingly became much harder for them to succeed in their studies. Putting support in place for the students 
was critical; with understanding of their personal circumstances, it had to be timely and appropriate for each individual. There was not one solution that fit all, and this also demanded flexibility on the part of the institution.

Prevalent inequalities, occurring in particular groups of students in arts education, mean that the populations of students studying creative subjects are predominantly young, white, female and from more affluent households. This has critical implications for the diversity of people entering into the creative industries.

As a WP practitioner, I admit to wondering about the sheer scale of the challenge that we face as a team located within a specialist subject institution. This includes deliberating on how we might reach out and make a significant impact upon individuals who are defined by a multitude of factors that present barriers and hurdles for progression in their lives. This quandary increasingly becomes the motivation and impetus for the development of my research skills. My WP research study finds that there are often multiple extenuating factors operating at one time in the circumstances of WP students; for example, falling behind with their work could be due to an undiagnosed learning difficulty or as a result of mental health. Other factors could include possession of a previous criminal record, returning to learning as a mature student, being a carer or experiencing financial insecurity.

The aim of widening participation programmes in education is to enable access to continuing education for individuals from underrepresented or disadvantaged groups. This is not only as a policy imperative, but also an educational priority, to achieve equity of access to PCE and the benefits that it brings. WP practitioners work in educational settings with students who, beyond the compulsory stages of their education in secondary school, have a choice to continue their studies and qualifications into post-compulsory education (PCE). The participation age in education (RPA) was raised in the United Kingdom to 18 years old in 2015. For the majority of younger students in England, PCE means the continuation of studies from Level 3 study in secondary school, Years 12 and 13 or in further education colleges to undertake Advanced Levels (A Levels) or BTEC (Business and Technology Education Council) qualifications, which enable progression into Levels $4-6$ of higher education undergraduate study.

The principle drivers for WP practice are equality, diversity and inclusivity (EDI) to provide fair and equitable access to education. WP practitioners champion social justice in education. The policy remit at work in this particular study is to provide fair access to PCE for anyone who has the desire and potential to continue their studies. This is generally achieved by providing timely, appropriate information and guidance on how to access HE. Opportunities are offered through campus visits or by WP practitioners going into schools and colleges, by providing creative skill development workshops, practical experience sessions, creative subject tasters, introductions to portfolio development seminars and mock interviews. The framework of activities offered also includes extra-curricular opportunities, such as an After-School Art club, holiday intensive sessions and engagements with exhibitions, cultural events and collections throughout the city and region. As a WP team, we deliver activities that utilise current arts students as role models and communicators to facilitate the delivery of programmes of WP.

The aims of WP, equality, diversity and inclusivity, are driven by wider government policies and regulatory legislation to encourage progression into PCE. In the case of HE, this is provided by the directives and guidance of the Office for Students (OfS) [1], which is the regulatory body for HE in England. The OfS issues guidance to HE providers to produce Access and Participation Plans to improve equality of opportunity for underrepresented groups to access, succeed in and progress from HE. It requires the HE providers to set stretching, outcome-based targets that are focused on gaps identified in an institutional self-assessment of their performance [1] (p. 3). The practices of WP and EDI are promoted and adopted by HE institutions (HEIs), not only as an act of compliance with the regulatory directives just described and as a statutory requirement for the higher education provider to be able to charge tuition fees above the basic rate, but also in the spirit of inclusiveness and fair access. The focus of the plans is on underrepresented groups, including students from areas of lower higher education participation, lower household income and/or lower socioeconomic status groups, 
some black, Asian and minority ethnic (BAME) students, mature students, disabled students and Care Leavers. [1] (pp. 16-17). The guidance also draws attention to a wider set of student groups, such as Carers, estranged students, Gypsy, Roma and Traveller communities, refugees and children of military families. [1] (p. 17)

The span of our programmes of widening engagement in the arts starts in early-years settings with primary school children, as well as with pre-sixteen young people (school years seven to ten), post-sixteen-year-olds (compulsory secondary education-years 11 to 13), with mature learners and with community groups, as well as parents, carers and key influencers.

Therefore, in WP practice, there is an annual cycle of interventions carried out with identified target cohorts in the drive to meet the ambitious and stretching targets demanded by politicians and policymakers. Targets, which we have to work towards, are set to change the demographic of the student population not only in the institution, but across PCE nationally.

We have to be mindful in our practice that WP, its goals and targets are achieved by putting into action plans that are set by the institution's strategic direction and the WP team's self-assessment and annual reporting processes. This is in order to ensure that, as WP practitioners, we meet targets set in institutions' Access and Participation plans that were approved by the regulatory body.

In practice, all of the stages of planning, delivery, reflection and evaluating occur at the same time. There is a reoccurring cycle of reflection upon the previous year (reflecting back)-refining of current plans for annualised monitoring, presenting evaluation returns of the impact that has-or has not-been achieved (as current reflection of impact of practice) while, at the same time, planning for future delivery.

\section{Materials and Methods}

In his publication 'On Becoming a Person-A Therapist's View of Psychotherapy', Carl Rogers opens the first chapter with the title: 'This is me' [2]. He writes about how he came to realise how hungry people are to know something of the person who is speaking to them and how this provides more context and meaning to his writing for others.

In this article, I attempt to provide you with an insight into my role as not only a practitioner, but as a researcher as well. I reflect upon the practitioner-researcher's positionality within professional practice. I therefore write as someone who is immersed in the context and the situation that is being researched. I am making my position as explicit as I can in order to try to throw new light upon knowledge in the field of widening participation (WP) practice. In this article, I present my own narrative of experience as a practitioner-researcher in the form of a recollection of my role's development in order to illuminate that experience.

In 'Widening Participation Practitioners Write!', Hudson [3] draws attention to the previous lack of support for WP practitioners in disseminating their work and writing for publication as an expected outcome of being a researcher. He concludes that:

'Developing a stronger voice through publication could also enable practitioners to have a greater influence in framing policy'. [3] (p. 131)

Developing a stronger voice through WP practitioner research and publication could indeed potentially enable a greater practitioner influence upon WP policy, as well as the development of research skills and a contribution to knowledge in the field of WP by dissemination to professional bodies and policy makers.

Wall, in 'Easier Said than Done: Writing an Auto-Ethnography' [4] (p. 39), states that it is 'an intriguing and promising qualitative method that offers a way of giving voice to personal experience for the purpose of extending sociological understanding'. However, she then warns that auto-ethnography can be a very difficult undertaking. She purports this method as a 'challenging yet highly promising form of inquiry'. Like Wall, I wish to present an 'authentic self' [4] (p. 41) and to make a 'scholarly contribution' [4] (p. 48) through this article. 
Geertz [5] provides another perspective on using oneself in an account by saying that 'to propose, after such a preamble, my own experience as a fit subject for review may seem to suggest a certain pretentiousness' [5] (p. 23). He goes on to say that he does not relate his research experiences because he considers them unique or special. Geertz then continues: 'Rather, I suspect them of being common to the point of universality among those engaged in similar work' [5] (p. 23). It is intended that, as a reader interested in WP and practitioner research, you may find synergy at points and divergence at others.

An aim of significant parts of this article is to give you a sense of the context in which I work and to act as a focus for shared reflective practice by providing insights into my experiences. My narrative is written from the perspective of someone who is immersed within the context of and with an interest in the field. This account is therefore written in the first person. I will begin by explaining my route into and the practicalities of engaging with the Education and Training Foundation (ETF) [6] Practitioner Research Programme (PRP) that is offered by the University of Sunderland Centre for Excellence in Teacher Training (SUNCETT). The Education and Training Foundation 'supports teachers and leaders across the Further Education and Training sector to help them achieve their professional development goals for the benefit of learners and employers across England' [6].

It is interesting to note how the practitioner-researcher aspect of my role has progressively developed, almost organically. This evolution has been actively encouraged as part of personal and continuing professional development, supported throughout by ETF via the Practitioner Research Programme (PRP) and by my own institution. This has enabled me to increase my professional knowledge and to establish a stronger voice in and for WP practitioners in the profession and for learners in the WP communities. This empowerment has come about as my own knowledge of the factors influencing the context of my work has expanded and through my engagement with research and literature in the field of WP. This, in turn, has increased my own understanding and that of others in related practitioner and research communities, particularly of the complexity of the situation regarding the lack of upward social mobility for marginalised individuals and the multiple contexts of disadvantage.

The context of this reflective article is set in the pursuit of policy initiatives that are designed to widen participation in education for underrepresented groups. I offer these glimpses into my research development journey so far, not in any kind of self-congratulatory way, but to indicate my positionality to you within my research study that I carried out as part of the PRP. I describe how I have come to arrive at this point in my own research journey and give an indication of the impact and reach of my development as a researcher and practitioner so far.

My route into and my experience of becoming a practitioner-researcher had started one summer term when I was encouraged by the Head of Research to apply for the RDF led by the SUNCETT team. This is a programme of research supported and funded by the Education and Training Foundation [6]. As the RDF programmes expanded, it later became known as the national Practitioner Research Programme (PRP).

To achieve a place on the programme, my application had first to be endorsed through a formal application for staff development support from the Human Resources department and gain approval by my line manager in my own institution. In addition, my application had then to be submitted to the Senior Management Team and the Research Committee for consideration. This resulted in a wrap-around package of not only support, but acknowledgment of the existence of my research in the context of the institution. Following application and an interview based on the research proposal, this led first to participation in a year-long RDF programme (an earlier version of the PRP) delivered by the SUNCETT team.

The RDF culminated in achieving a 30 credit Master of Arts module in Practitioner Research. This acted as a stepping-stone to becoming a practitioner and researcher. Following the Fellowship, I was then in a position to apply to be part of a two-year, bespoke Master of Philosophy (MPhil) in Practitioner Research, a programme of research also supported by the ETF and SUNCETT. At the end 
of year two of the MPhil programme, I could then apply to transfer to doctoral-level study. I was required to complete a formal Annual Monitoring Review, submit a progress report and engage in a Viva Voce examination. This enabled me to advance my studies to become a student at the doctoral level as a practitioner-researcher alongside my role in the university. I continue to receive support for this research development and from SUNCETT through the supervision of my studies.

To reflect upon on the impact of participating in the PRP is to find that it has undoubtedly moved my career as a WP practitioner forward. In terms of impact, my research practice means I have now joined the university's research community. My research activity is regularly reported and noted by the same committee. It has also been included in the university's annual equality, diversity and inclusivity report as developing knowledge- and research-informed practice to achieve strategic measures for equity of access for all groups of students. The output of research posters, abstracts, presentations and papers is placed on the university's online research repository, 'CREST' (Consortium for Research Excellence Support and Training) [7]. I also now possess a research identifier number, 'ORC ID' [8], which is an online global signifier of being active in research.

My research profile has grown alongside my role and responsibilities. The University participates in the regional partnership of the National Collaborative Outreach Programme (NCOP), which is an Office for Students (OfS) project in England. Over Phase 1 of the collaborative project, I was a member of a steering group for the regional partnership. I now have a role as the Vice-Chair of the Access and Participation Strategy Group in the partnership. Through liaison, networking and debate with other colleges and universities, I am able to influence WP delivery with the deepening of knowledge in the field. This recognition elevates the reach and impact of both my practice and research beyond the institution. Development in my role and research also contributes to the national professional networks and associations that are connected to my practice for WP, equality, diversity and inclusivity in education. This means that the research and knowledge that I gained in the field contribute to a greater sphere of practice beyond that which is focused on my institution.

One highlight of my researcher development has been to attend and present at an All-Party Parliamentary Group (APPG) in Arts, Craft and Design education held at the Houses of Parliament. This was to make a joint presentation to the APPG of Broadhead's research into mature learners in the arts [9]. We presented a range of inclusive practices that the university that has put into place in order to support mature learners' progression from further education into higher education. The framework of interventions and support is presented in a diagram in a research poster [10] that visually represents a progression framework of support for students that spans the whole student lifecycle from pre-university, through undergraduate study and progression into employment. The interventions in the framework were developed and have evolved through listening to the voices of mature learners over time and refining practice.

Continuing my interest in the processes of policymaking, I also attended a 'Women Researchers in the UK Parliament' [11], which was a research development day held at Westminster, London where we discussed the ways in which researchers can inform and influence at parliamentary and ministerial levels.

Through the undertaking of my research study and development, I am endeavouring to make a new and hopefully useful contribution to knowledge regarding professional practice, curriculum design and pedagogy in WP through my research practice and the dissemination of my work.

\section{Research Methodology for the Main Research Study}

It is not possible within the constraints of this article, which focuses on the reflections of a practitioner researcher in PCE, to fully describe my main research study. I undertook thematic analyses of narratives of highly engaged arts students in my institution through narrative inquiry. My main research methods are to determine what categories of critical incidents and influences had led the students to progress into the arts. This takes heed of the students' voices and, through analysis, identifies emergent themes with the aim of informing the co-design and co-production of outreach curricula and 
pedagogic activities to aid progression for disadvantaged groups. This research is intended to inform WP professional practice through collaborative curriculum design and inclusive pedagogy. There is a pressing need to understand how we can collectively surmount those hurdles, depending on the extent to which participation in and experience of widening participation interventions, delivered by institutions, are able to address matters of inequality and injustice.

As its ontological starting point, my main research study takes an interpretivist view of the social world. It seeks to understand and interpret experience. The narratives of students' experiences are employed to access, interpret and analyse the subjective and intersubjective experiences of the individuals involved in the study. The epistemological approach I have taken is pragmatic in that the origins of this study emerged from a context and problem encountered in my professional practice with the need to improve outreach interventions in PCE.

Immersion in the literature in this field of study identifies key texts from a number of disciplines, including education, philosophy, psychology and sociology. The debate continues on whether education can or cannot compensate for society, examined through the works of Bernstein [12], Gorard [13] and Coffield and Willliamson [14], and this resides at the core of my research study.

As my research study progressed, it became important to be able to delve deeper into understanding of the context of inequalities of access to PCE that are creating the under-representation of particular groups in the student populations involved in the study. It also became important to understand how the reality of experience of contexts of disadvantage is so much more complicated in practice than that which can be encompassed by a single definition of one group.

As the WP Outreach Progression team, we are tasked in our roles with the design and delivery of interventions of targeted outreach and engagement for all age groups in education. Our enduring endeavour is to reach out to individuals in disadvantaged contexts. Earlier in this article, it was established that political, policy and institutional imperatives are setting ambitious and challenging remits to increase access and widen participation through outreach. These provide us with our sense of purpose and make our WP roles all the more interesting.

This becomes a WP 'landscape of practice'; a term adopted by Wenger-Trayner and Wenger-Trayner [15] in 'Learning in Landscapes of Practice: Boundaries. Identity and Knowledgeability in Practice-Based Learning'. To quote them on the complexity of the landscape of practice where they indicate the volatility of the context, they point out that:

'The composition of such a landscape is dynamic as communities arise and disappear, evolve, merge, split, compete with or complement each other, ignore or engage the other'. [15] (p. 15)

An empirical underpinning of the context and problem that this research study investigates is demonstrated within the Children's Commissioners' 'Vulnerabilities Report 2018' [16]. This was the second attempt to produce a report of its kind, and it throws a light on a count of young people in England aged up to 17 years and caught up in 70 different categories of vulnerabilities. The Children's Commissioners' report [16] reveals a snapshot of the population of young people in England at a point in time and draws attention to the scale and complexity of the problematic 'disadvantaged' contexts for many. This report was achieved by bringing together a number of different surveys and counts by different organisations, all having different parameters of criteria for inclusion. The technical description of the metrics [17] for the report speaks of gaps in the data and the problem of overlapping datasets, as well as the occurrence of the unaccounted for and hidden numbers of children. The fact that the number of vulnerability categories amounts to 70 subsets indicates the sheer complexity of contexts of deprivation and disadvantage within populations that may consequently be less likely to consider progression to PCE. Exposure to this information of gaps, hidden numbers and unknowns has been a strong influence within my own research.

Hutchinson et al. [15] argue that there is 'too great a focus on single communities' [15] (p. 1) and that there are 'multi-memberships in different communities' arguing - that it 'obscures the multiple communities that students belong' [15] (p. 2). 


\section{Results}

This article is a reflection upon of the impact of being immersed in a practice-based research study and is presented as an auto-ethnographic account. It is intended to provoke your own reflection upon your experiences of engaging in research in your field of study. It is also an invitation to contribute to a conversation about the value and importance of WP practitioner-research in PCE.

The prime intention is to provide an account of my own experiences of conducting research as a PRP practitioner-researcher in order to offer insights into these experiences and give a sense of the conduct of WP study. This article is therefore less about research themes that are emerging from the narratives in my WP research study, although they have been touched upon briefly.

\section{Discussion}

As WP practitioners, it seems that we are caught up in triangulations or lynchpins of pressures of directives from different bodies, such as from the government and the education policy makers, as well as from the institution's own strategic vision, the mission statement and the objectives that it prioritises. Finally, within the mix are our personal and professional practitioner selves and how our own 'ethos' and virtues shape our part as practitioners in the equation of WP engagement.

WP practitioners, through their outreach interventions, have to ensure that their actions create sufficient impact to reach out to many and to affect individuals' decision-making. At the same time, WP evaluation has to be accountable simultaneously to both the government and the institution.

Wenger-Trayner and Wenger-Trayner [15] (p. 99) describe 'Systems Conveners'. Inspirationally, they state that Systems Conveners

'attempt to reconfigure the landscape; unlocking unexplored spaces-forging promising partnerships—building bridges—resetting boundaries—challenging established colonies and creating new settlements'. [15] (p. 100)

As a WP practitioner, I recognize the dynamics identified by the above authors, which they describe as 'systems convening', articulating the dynamic nature and interaction of roles and responsibilities in pursuit of widening participation. There is a kind of pleasure in facing and overcoming the challenges of working across systems and boundaries already established within educational institutions. WP as a practice constantly questions, tests, examines, blurs and fuses the boundaries of current educational practice in PCE in its endeavour to create the systemic change necessary to become a reality in practice.

My main research study suggests that current definitions of underrepresented groups may be overly simplistic; often in reality, there are combinations of several factors influencing educational disadvantage present for any one student at one point in time.

\section{Practitioner Research in WP}

Now, some issues in relation to the role of being a practitioner-researcher in the context of WP in England will be considered. The British Educational Research Association (BERA) [18] defines quality in 'Close-to-Practice' (CtP) research as:

'High-quality close-to-practice research requires the robust use of research design-theory and methods to address clearly defined research questions, through an iterative process of research application. The research process will be well documented and the conclusions that are drawn will be appropriate to the strengths and weaknesses of the design, theory and methods used. Such research will draw upon practitioners' and researchers' reflections on both practice and context'. [18]

This definition regarding the relationship between evidence-informed policy and practice [18] (p. 15) is helpful in drawing attention to situations in education practice that might be seen as problems shared by practitioners, researchers and policymakers alike. 
An interpretation of the BERA definition of practitioners and researchers is that it addresses them as if they are separate individuals. The separation of practitioner and researcher may be seen to be problematic. It adds to the assumption of the existence of a dichotomy between research and practice. This is clearly not the case in practitioner-research in real life. The practitioner is also the researcher; a closer integration of these activities or separation would be difficult, if not impossible to achieve. However, the CtP definition also refers to 'an iterative process of research application that includes reflections on practice, research and context' [18]. In this situation, the action of research and the action of practice become one, fused in the act of practitioner-research.

Kemmis [19] (p. 1), on theorising educational practice, argues that 'practitioners are not mindless functionaries performing in accordance with the theories of others'; nor does he accept the apparent recognition that practice and theory develop reflexively and together. He points out that many researchers still proceed to study practice 'from the outside'.

Robson in 'Real World Research' [20] states:

'The practitioner-researcher is someone who holds down a job in some particular area and at the same time carries out systematic enquiry which is of relevance to the job'. [20] (p. 446)

Robson reminds us of 'insider problems' of experience based on the situation and the people involved. He also points to the increasing acceptance that investigation, enquiry, evaluation and innovation are all part of the professional role [20] (p. 447).

The role of being a WP practitioner demands that we keep abreast of current developments in research and knowledge in the subject to ensure that we remain informed practitioners, constantly monitoring, evaluating, reflecting and refining our practice in a constantly changing field of politically and ethically driven processes of education. This includes the motivation to integrate research and practice, to make a contribution to the field of knowledge, to enter into a community of research and practice and to be able to operate strategically. Robson [20] and Kemmis [19] argue that the dissemination and sharing of practice and research findings as the work of practitioner-researchers' progress that then moves the field of knowledge forward.

One disadvantage of conducting systematic practitioner research is the sheer amount of time that it takes. In my experience of the PRP, systematic practitioner research requires a gestation time, a maturing and deepening of knowledge, through a sustained period of immersion in the canon of literature; this is to enable the development of an understanding of the context and the problem of the subject being researched. Ethical approval has to be established by submission to committees of research ethics for scrutiny. The research design of the interventions, methods and methodology emanate from the research aims and objectives as the gap(s) in knowledge are identified.

The previous paragraphs on practitioner research and research practice are essentially describing very related processes. However, in the cycle of WP practice, there is a marked difference in the pace of delivery and its expected impact upon its recipients. I think that all of the processes previously described have to run concurrently. The turn-around of expected and looked-for results is much more immediate. In terms of the ethics of providing equity of opportunity, just one moment or a pause in delivery within the short cycle in one school year potentially means that, for the whole year, cohorts of young people may miss out on opportunities and experiential learning that their participation in outreach interventions can bring at important points of their education journey.

My understanding of the research process has developed through my part in research practice, as it underscores how the momentum of WP engagement has to be sustained. WP and the provision of research opportunities have to fit around and into the gaps that an already conflicting and compressed timetable that compulsory stages of education offer.

Bernstein [21] (p. 78) offers a definition of 'pedagogy' as a 'sustained process whereby somebody(s) acquires new forms or develops existing forms of conduct, knowledge, practice and criteria from somebody(s) or something deemed to be an appropriate provider and evaluator'. One aspect of a great deal of WP pedagogy is that it is currently situated at the edges of mainstream education in curriculum 
design and delivery. In an article entitled 'Social mobility is a postcode lottery: Too many in Britain are being left behind', Milburn [22] comments on current practice, where he states:

'There is-however-a mind-blowing inconsistency of practice. All too often, schemes start up and then wither away; initiatives lack scale; experience is not pooled; evidence is not embedded properly or ignored.'. [22]

This is a profound criticism put forward by Milburn relating to the pursuit of WP in the contexts and in the face of the challenges encountered by WP practitioners. Their role is to make a difference in circumstances for participants through outreach interventions to convey the merits of continuing education and qualification. It is necessary for practitioners to evidence the impacts of interventions that are successful in changing the group demographics in student populations. I argue that it would be a social injustice to remove the intervention of widening participation programmes in education.

However, what aspects of WP practices are the most likely to succeed? Looking to Schön and his writing on the 'Reflective Practitioner', he concludes that:

'The extent of our capacity for reciprocal reflection-in-action can only be discovered through an action science which seeks to make what some of us do on rare occasions into a dominant pattern of practice'. [23] (p. 354)

I argue that in conducting WP practice 'reflection-in-action' is what practitioners have to do as part of their daily working practice. However, there is a dilemma that haunts practitioner research regarding current aspects of WP practice. Deeper research into WP is in danger of becoming shortcut. There is a risk of it becoming an ad-hoc and poor facsimile of research if it is not sustained in nature, carefully considered or given the opportunity of undergoing a thorough and well-conducted process of research design. The sheer pace of conducting practitioner research, alongside the demands of delivering practice, is perhaps closer to the reality of being an educational researcher and far removed from the idealised utopia that I once pictured the process of carrying out systematic research in education to be.

What do we mean by good educational practice in WP contexts? Sennett [24] argues that two issues drive quality-driven work:

'The first is the craftsman's desire to do good work; the second lies in the abilities required to do good work'. [24] (p. 241)

This article notes that in WP, practitioners, by the nature of their role, desire to do good work, and this is part of their purpose within the PCE institution. I argue that the desire to do good work is also one of the reasons for why WP practitioners take on their role in the first place. The extent to which it is possible to find the space and capacity to conduct systematic research in an already busy calendar of WP curriculum planning and pedagogic delivery and to achieve real meaningful reflection in the process is, of course, quite another matter.

This is why being able to carry out recognised and supported systematic educational research, in order to bring to light the findings of practitioner research and provide a contribution to knowledge that is underpinned by a thorough literature review and carries the institution's ethical approval of its approach, becomes vital to the quality of educational research and the improvement of educational practice in WP contexts.

It is necessary to have the ability to present and justify a considered methodology that emanates from the context and addresses the problem, which then results in careful research design with sustained data collection and analysis. The generation of evidence derived from research-informed activity and identification of indicators of impact is paramount in all of this. From this perspective, systematic practitioner research in WP is not only of importance, but it is in fact a necessary condition for the development of good practice in WP, not a luxury.

To reflect further upon my own journey as a practitioner-researcher, I have not personally experienced a lack of support either in my role or in receiving encouragement to write for publication. 
In practice, WP practitioners regularly contribute evaluative reports and papers to inform the deliberative structures of their institutions' committees and their Boards of Governors. This not only to provide evidence that due process has been done, but also that funding is well spent. Writing for dissemination and the sharing of good practice with professional networks is a pragmatic step forward for WP practice.

As WP practitioners, we work daily alongside current students who take on the role of Student Ambassadors. I confess to being very impressed by these students as individuals, how they manage their time and studies and give their energy and support in WP outreach delivery alongside their other commitments, including the professional skills that they develop or demonstrate through acquiring this work experience. They champion their subject of study and act as role models, enabling younger cohorts to identify with them as examples of students who are just a few steps ahead in their education journeys. My research practice and development have enabled me to gain an insight into their experiences and motivations in the arts. I am looking forward to building upon this knowledge that I have gained to move WP outreach pedagogy forward.

\section{Summary and Conclusions}

This article presents an auto-ethnographic account of a WP practitioner who is developing her practitioner research skills; it discusses the challenges of combining practice and research concurrently and presents an account of how immersion in that development of research skills and conducting research creates change in professional practice.

To draw a tentative conclusion: Undertaking practitioner research, increasing knowledge and making contributions to knowledge in the contexts of WP has assisted in creating a contribution to this field of knowledge. In turn, it also contributes to the discourse surrounding WP practices.

As a professional practice, WP requires understanding and empathy of the needs of individuals and groups who are situated in contexts that hold back the potential of some groups of people and advantage others. However, the context that WP operates in is socially and politically complicated. The context of the difficulty of achieving social mobility is a vast subject that infiltrates all aspects of life.

In closing, I am arriving to a conclusion that concurs with Coffield and Williamson [14], where they argue that 'education cannot compensate for the effects of society alone'. A deeper and sustained multi-agency approach to support across the whole educational pathway for individuals is required.

I would add that widening participation is an important aspect of leading a fulfilled life, as is, as I have found, conducting research in your own practice, as perhaps this auto-ethnographic account of my experience as a WP practitioner-researcher demonstrates.

Through carrying out practitioner research within my role as a WP practitioner, I have been privileged to have access to the voices provided by participants within my research study, to have been able to conduct thematic analysis of their experiences of their journey into the arts and to begin to apply this knowledge in day-to-day WP practice. Through my research skills and development, it has become evident to me that student-informed WP practice and working with students as co-producers of aspects of the WP programme design, utilising their experience, might be the way forward in co-designing the WP curriculum.

To quote Holman Jones [25]:

'Stories make you curious. They tell you about yourself and other people. They help you figure things out, and then show you how to live life'. [25] (p. 670)

Holman Jones also writes that auto-ethnography offers her a way of writing, experiencing and understanding a number of moments, turns and absences in her life; the power of story in her life as a scholar [25] (p. 670). I hope that this article of my auto-ethnographic account of a WP practitioner-researcher has been helpful in offering some insights into the experiences and realities of practitioner research, particularly in the context of equity of access to continuing education. It is 
anticipated that it may be of interest to other researchers working in the field of WP and that they will accept my invitation to contribute to this conversation.

Author Contributions: All authors have read and agreed to the published version of the manuscript. Writing — Original draft preparation: M.B.; Writing—Review and editing: M.G.; and MDPI. Supervision: M.G.

Funding: The funders of my research had no role in the design of the study, in its collection, analysis or interpretation of the data in the writing of the manuscript or in the decision to publish the results.

Conflicts of Interest: The author of this article declares no conflict of interest.

\section{References}

1. Office for Students (OfS). Regulatory Notice 1: Access and Participation Plan Guidance. 2019. Available online: https://www.officeforstudents.org.uk/publications/regulatory-notice-1-access-andparticipation-plan-guidance/ (accessed on 9 April 2020).

2. Rogers, C. On Becoming a Person-A Therapists View of Psychotherapy; Houghton Mifflin Company: Boston, MA, USA, 1961.

3. Hudson, A. Widening Participation Practitioners Write! In Transformative Higher Education-Access, Inclusion $\mathcal{E}$ Lifelong Learning; FACE (Forum for Access and Continuing Education): London, UK, 2019.

4. Wall, S. Easier said than Done: Writing an Auto ethnography. In International Journal of Qualitative Methods; International Institute for Qualitative Methodology (IIQM), University of Alberta: Alberta, AB, Canada, 2008.

5. Geertz, C. Available Light; Princeton University Press: New Jersey, NJ, USA; Oxfordshire, UK, 2000.

6. Education Training Foundation (ETF). Available online: et-foundation.co.uk/about-us/welcome-educationtraining-foundation/ (accessed on 9 April 2020).

7. CREST. Available online: https://lau.repository.guildhe.ac.uk/cgi/search/simple?q=Baines\&_action_search= Search\&_order=bytitle\&basic_srchtype=ALL\&_satisfyall=ALL (accessed on 17 November 2019).

8. ORCID. Available online: https://orcid.org/0000-0002-7300-7188 (accessed on 7 May 2020).

9. Broadhead, S. Mature students, transformation and transitions. Emerald Insight, Education and Training. Available online: https://lau.repository.guildhe.ac.uk/17299/ (accessed on 17 November 2019).

10. Baines, M.; Broadhead, S. The Art of Surviving and Thriving. Research Poster. 2018. Available online: https://lau.repository.guildhe.ac.uk/17486/1/The\%20art\%20of\%20surviving\%20and\% 20thriving\%20Baines\%20\%20Broadhead\%20\%2014\%2002\%2018\%20final.pdf (accessed on 7 May 2020).

11. UK Parliament. Women Researchers at the UK Parliament. 2019. Available online: https://Parliament.uk/get-involved/research-impact-at-the-uk-parliament/training-and-events/womenresearchers-at-the-uk-parliament/ (accessed on 12 January 2020).

12. Bernstein, B. Education Cannot Compensate for Society; Routledge Falmer: London, UK, 1970.

13. Gorard, S. Education can compensate for society-A bit. 2010. Available online: https://research. birmingham.ac.uk/portal/files/2920093/Gorard_2010_British_Journal_of_Educational_Studies.pdf (accessed on 17 November 2019).

14. Coffield, F.; Williamson, B. From Exam factories to Communities of Discovery: The Democratic route. Bedford Way Papers Series; Institute of Education: London, UK, 2012.

15. Wenger-Trayner, B.; Wenger-Trayner, E.; Fenton-O-Creevy, M.; Hutchinson, S.; Kubiak, C. Learning in Landscapes of Practice: Boundaries, Identity and Knowledgeability in Practice Based Learning; Routledge: Oxon, UK; New York, NY, USA, 2015.

16. Children's Commissioner. Vulnerability Report 2018; Children's Commissioner's Office: London, UK, 2017.

17. Children's Commissioner. Constructing a definition of Vulnerability-Attempts to Define and Measure; Technical paper 1; Coram and Coram International: London, UK, 2017.

18. BERA. BERA Statement on Close to practice Research. Available online: https://www.bera.ac.uk/publication/ bera-statement-on-close-to-practice-research (accessed on 13 January 2020).

19. Kemmis, S. Theorizing Educational Practice' in Carr, W. For Education. towards Critical Education Inquiry; Open University Press: Buckingham, Philadelphia, 1995.

20. Robson, C. Real World Research. In A Resource for Social Scientists and Practitioner Researchers; Blackwell: Oxford, UK; Cambridge, MA, USA, 1993. 
21. Bernstein, B. Pedagogy, Symbolic Control and Identity. In Theory, Research, Critique; Rowan and Littlefield Publishers, Inc.: New York, NY, USA; Oxford, UK, 1996.

22. Milburn, A. Social mobility is a postcode lottery. Too many in Britain are being left behind. 2017. Available online: https:/www.theguardian.com/inequality/2017/nov/28/social-mobility-stark-postcodelottery-too-many-britain-left-behind-alan-milburn-commision-report/ (accessed on 3 June 2018).

23. Schon, D. The Reflective Practitioner. In How Professionals Think in Action; Ashgate: London, UK, 1991.

24. Sennett, R. The Craftsman; Penguin Books Ltd.: London, UK, 2009.

25. Holman Jones, S.; Adams, T.; Ellis, C. Handbook of Auto Ethnography; Routledge: Oxon, UK; New York, NY, USA, 2016.

(C) 2020 by the authors. Licensee MDPI, Basel, Switzerland. This article is an open access article distributed under the terms and conditions of the Creative Commons Attribution (CC BY) license (http://creativecommons.org/licenses/by/4.0/). 